\title{
Hepatitis B virus core antigen as a carrier for Chlamydia trachomatis MOMP multi-epitope peptide enhances protection against genital chlamydial infection
}

\author{
Pengfei Jiang ${ }^{1, *}$, Wangqi Du ${ }^{1, *}$, Yirong Xiong ${ }^{1}$, Yan Lv ${ }^{1}$, Juan Feng ${ }^{1}$, Shanli Zhu ${ }^{1}$, \\ Xiangyang Xue ${ }^{1}$, Shao Chen ${ }^{1}$ and Lifang Zhang ${ }^{1}$ \\ ${ }^{1}$ Institute of Molecular Virology and Immunology, Department of Microbiology and Immunology, School of Basic Medical \\ Sciences, Wenzhou Medical University, Wenzhou, Zhejiang, P. R. China \\ * These authors have contributed equally to this work \\ Correspondence to: Lifang Zhang, email: wenzhouzlf@126.com \\ Keywords: HBCAg, chlamydia trachomatis, major outer membrane protein, multi-epitope peptide, vaccine, Immunology and \\ Microbiology Section, Immune response, Immunity \\ Received: September 15,2015 Accepted: November 26, $2015 \quad$ Published: December 09, 2015
}

\section{ABSTRACT}

Chlamydia trachomatis $(\mathrm{Ct})$ is the leading cause of sexually transmitted diseases worldwide. There is no safe and effective vaccine to control the spread of $C t$. In development of $\boldsymbol{C t}$ vaccine, selection of appropriate candidate antigens and an effective delivery system may be the main challenges. Multi-epitope of major outer membrane protein (MOMPm) is the most suitable candidate for a Ct vaccine, while hepatitis B virus core antigen ( $\mathrm{HBCAg}$ ) has unique advantages as vaccine delivery system. Therefore, in this study, we evaluated the immunogenicity and protective immune response of a novel candidate vaccine in a murine model of chlamydial genital infection. This candidate vaccine comprises MOMPm peptide delivered with HBCAg. Our results of Ct-specific serum IgG and secretory IgA assay, cytokine assay, and cytotoxic T-lymphocyte assay revealed that immunogenicity of the candidate vaccine was much better than that of the corresponding synthetic MOMPm peptide. Furthermore, the protective effect of the candidate vaccine was also shown much better than that of the synthetic peptide by calculating the isolation of Chlamydia from vaginal swabs and histopathological analysis. Taken together, our results indicate that HBcAg carrying Ct MOMPm could be an effective immune prophylactic for chlamydial infection.

\section{INTRODUCTION}

Chlamydia trachomatis $(C t)$, an obligate intracellular parasite, is the main cause of preventable blindness and the leading cause of bacterial sexually transmitted diseases worldwide [1]. The World Health Organization estimates that almost 100 million chlamydial cases occur each year [2]. Although very effective antimicrobial therapy is available, chlamydial infection can recur easily. Therefore, the best and most economical solution to control or eradicate the spread of $C t$ is to develop safe and effective vaccines. Although considerable effort has been expended toward this goal, an effective vaccine has not yet been developed.

Current challenges in the development of $C t$ vaccine include selection of appropriate candidate antigens and an effective delivery system [3]. Therefore, it is necessary to identify protective $C t$ antigens or epitopes in animal models. The major outer membrane protein (MOMP), one of the highly conserved surface associated proteins among the different serotypes of $C t[4,5]$, may be the most suitable candidate for a $C t$ vaccine because it contains both T- and B-cell epitopes that can induce specific anti$C t$ immune responses. However, it is difficult to produce recombinant MOMP in a native form on a scale large enough to be commercially viable [6]. At present, multiepitopes of MOMP (MOMPm), T- and B-cell epitope-rich clusters, were selected to design $C t$ vaccines.

It is reported that synthetic epitope peptides are weak immunogens and may limit the potential protective immune responses [7]. To enhance the immunogenicity of multi-epitope, it can be fused to an innocuous but highly antigenic protein, such as the Hepatitis B virus core antigen $(\mathrm{HBcAg})$. $\mathrm{HBcAg}$ can self-assemble into viruslike particle (VLP) and has been generally used as vaccine 
delivery system [8]. As reported in previous studies, through genetic fusion, the HBcAg protein lends itself to accommodate foreign epitopes in three ways: antigens can be linked to the $\mathrm{N}$-terminus or C-terminus of $\mathrm{HBcAg}$, or inserted into the major immunodominant region (MIR) of $\mathrm{HBcAg}$ [9]. In consideration of the fact that $C t$ serovars $\mathrm{D}$ and $\mathrm{E}$ were the most predominant serovars prevalent worldwide [10-12], in this study, we assessed the HBcAg platform as a delivery system for MOMPm of $C t$ serovar E. Our results showed that the fusion of MOMPm to $\mathrm{HBcAg}$ induced specific protective immune response against genital chlamydial infection and that different ways of $C t$ MOMPm fused with $\mathrm{HBcAg}$ could induce different levels of protective immune response against genital chlamydial infection.

\section{RESULTS}

\section{Obtainment of $C t$ MOMPm and formation of HBcAg/MOMPm chimeric VLPs}

Several peptides containing both HLA and H2 restricted cytotoxic T-lymphocyte (CTL)/Th epitopes were screened by analyzing the amino acid sequence of $C t$ MOMP, from which the peptide of MOMP $_{370-387}$ containing the reported B-cell epitope (TRLIDERAAH) [13] was selected to be a candidate for MOMPm (Figure 1A).

The recombinant vectors, pET21a(+)/HBcAg, pET21a(+)/HBcAg/Ct-MOMP ${ }_{370-387}, \mathrm{pET} 21 \mathrm{a}(+) / \mathrm{HBcAg} /$ $\mathrm{Th} / \mathrm{Ct}$-MOMP $\mathrm{M}_{30-387}, \quad \mathrm{pET} 21 \mathrm{a}(+) / \mathrm{Th} / \mathrm{Ct}-\mathrm{MOMP}_{370-387} /$ $\mathrm{HBcAg}$ and pET21a $(+) / \mathrm{HBcAg}-\mathrm{MIR} / \mathrm{Th} / \mathrm{Ct}-\mathrm{MOMP}_{370-387}$ were confirmed to be constructed successfully by indicated restriction endonuclease digestion and sequencing. The structure of these vectors was shown in Figure 1B. The corresponding recombinant proteins were expressed, purified and confirmed by SDS-PAGE and western blot analysis. As shown in Figure 2A, 2B and 2C, the proteins with expected weights were detected. The formation of
A

KYAVTVETRLIDERAAHV
KYAVTVETRLIDERA
KYAVTVETRL
KYAVTVETRL
TVETRLIDER
TRLIDERAAH
RLIDERAAHV

$C t-\mathrm{MOMP}_{370-387}$ peptide

HLA-DRB $1 * 0401$

HLA-A*24:02

$\mathrm{H} 2-\mathrm{Kd}$

HLA-A*11:01

$B$ cell epitope

HLA-A*02:01

B

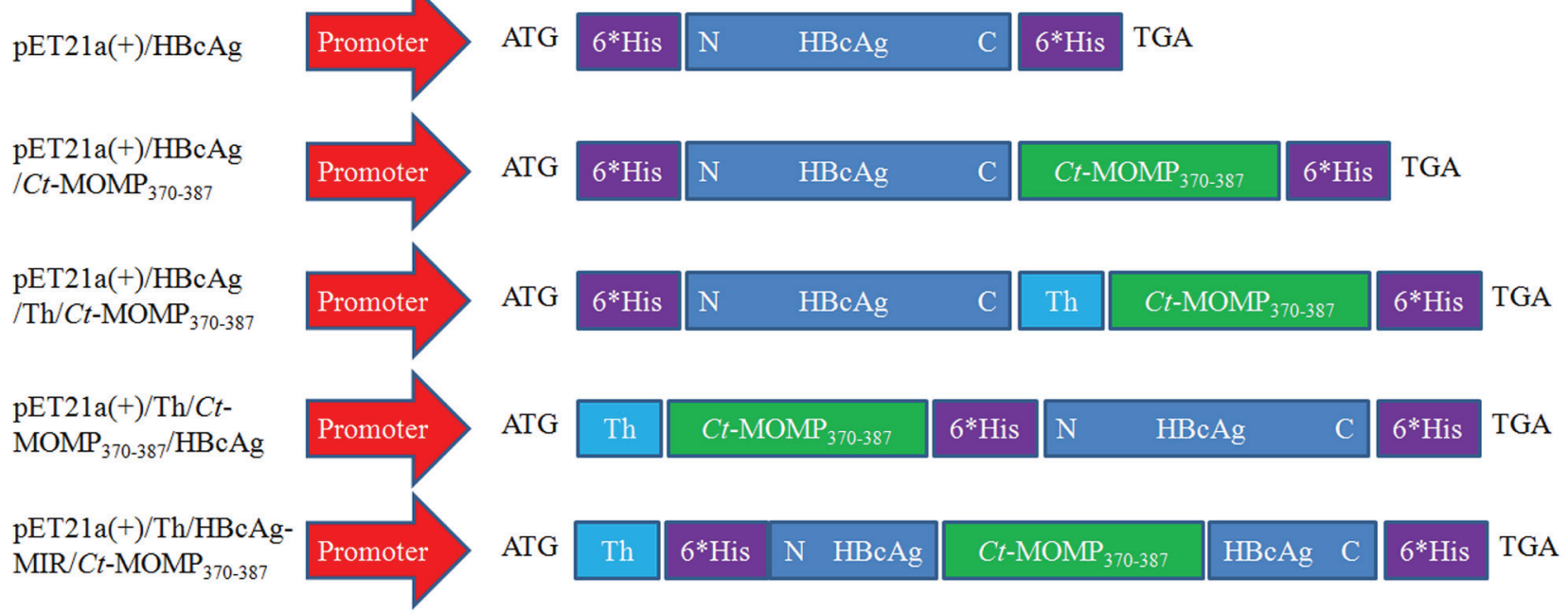

Figure 1: Prediction of $\boldsymbol{C t}$ MOMPm and construction of three kinds of recombinant vectors. A. Schematic representation of epitopes contained in the $\mathrm{MOMP}_{370-387}$ peptide. B. Schematic representation of three kinds of recombinant vectors. "N" or "C" means $\mathrm{N}$-terminus or C-terminus of $\mathrm{HBcAg}$ sequence, respectively. "Th" means the universal helper T-lymphocyte epitope (PADRE). " 6 *His" means 6 His-tags. 
VLPs was observed by negative-stain electron microscopic analysis (Figure 2D).

\section{Immunogenicity of $\mathrm{HBcAg} / \mathrm{MOMPm}$ chimeric VLPs}

Serum cytokine concentrations were assayed at week 8. As shown in Figure 3A and 3B, compared with negative control groups (PBS and $\mathrm{HBcAg}$ ), the secretion of the IFN- $\gamma$ (produced by Th1 cells) and the IL-4 (produced by Th2 cells) in test groups was both significantly increased. Among the five test groups (synthetic $C t-\mathrm{MOMP}_{370-387}$ peptide $\quad\left(\mathrm{s} \mathrm{C} t \mathrm{MOMP}_{370-387}\right), \mathrm{HBcAg} / C t-\mathrm{MOMP}_{370-387}$, $\mathrm{HBcAg} / \mathrm{Th} / \mathrm{Ct}-\mathrm{MOMP}_{370-387}, \mathrm{Th} / \mathrm{Ct}-\mathrm{MOMP}_{370-387} / \mathrm{HBcAg}$, and $\mathrm{HBcAg}-\mathrm{MIR} / \mathrm{Th} / \mathrm{Ct}$-MOMP ${ }_{370-387}$ ), the secretion of IFN- $\gamma$ and IL-4 in groups of $\mathrm{HBcAg} / \mathrm{Ct}-\mathrm{MOMP}_{370-387}$, $\mathrm{HBcAg} / \mathrm{Th} / \mathrm{Ct}-\mathrm{MOMP}_{370-387}, \mathrm{Th} / \mathrm{Ct}-\mathrm{MOMP}_{370-387} / \mathrm{HBcAg}$ and $\mathrm{HBcAg}-\mathrm{MIR} / \mathrm{Th} / \mathrm{Ct}-\mathrm{MOMP}_{370-387}$ was significantly increased compared with the group of $\mathrm{sCt}$-MOMP Especially, the secretion of these two cytokines in groups of $\mathrm{HBcAg} / \mathrm{Th} / \mathrm{Ct}-\mathrm{MOMP}_{370-387}, \mathrm{Th} / \mathrm{Ct}-\mathrm{MOMP}_{370-387} / \mathrm{HBcAg}$ and $\mathrm{HBcAg}-\mathrm{MIR} / \mathrm{Th} / \mathrm{Ct}$-MOMP ${ }_{370-387}$ was similar to that in positive control group (The inactivated $C t$ elementary body was called inactivated $C t$ (EB) for short.).

Previous studies indicated that both $\mathrm{IgG}$ and secretory IgA could protect against genital chlamydial infection [14]. Therefore, the level of these antibodies in the serum and vaginal secretions of immunized mice was determined by ELISA. Except negative control groups, the level of $C t$-specific serum IgG in test groups and positive control group rose gradually after immunization and reached the highest point during week 6 to 8. Among these five test groups, immunization with $\mathrm{HBcAg} / \mathrm{Th} / \mathrm{Ct}$ MOMP $_{370-387}$ induced higher level of IgG than the $\mathrm{HBcAg} /$ $C t$-MOMP ${ }_{370-387}$ group. Furthermore, immunization with $\mathrm{Th} / \mathrm{Ct}$-MOMP ${ }_{370-387} / \mathrm{HBcAg}$ induced the highest level of $\mathrm{IgG}$, which was significantly higher than that induced by $\mathrm{HBcAg} / \mathrm{Th} / \mathrm{Ct}$-MOMP ${ }_{370-387}$ and $\mathrm{HBcAg}-\mathrm{MIR} / \mathrm{Th} / \mathrm{Ct}$ MOMP $_{370-387}$ (Figure 4A).

Except negative control groups, the level of $C t$-specific sIgA in vaginal secretions in test groups and positive control group also rose gradually after immunization. The level of $\operatorname{sgA}$ in all of the test groups reached the highest point at week 6 and then decreased at week 8 . Among the test groups, at week 6 , immunization with $\mathrm{Th} / \mathrm{Ct}$-MOMP ${ }_{370-387} / \mathrm{HBcAg}$ induced the highest level of sIgA, followed by $\mathrm{HBcAg} / \mathrm{Th} / \mathrm{Ct}-\mathrm{MOMP}_{370-387}$. Furthermore, the level of sIgA in these two groups was both significantly higher than that in the group of $\mathrm{HBcAg}$ / $C t$-MOMP ${ }_{370-387}$. The level of sIgA in the group of $\mathrm{HBcAg} /$ $C t$-MOMP ${ }_{370-387}$ was significantly higher than that in the group of sCt-MOMP ${ }_{370-387}$ (Figure 4B).

The cytotoxicity of splenic lymphocytes from the

A

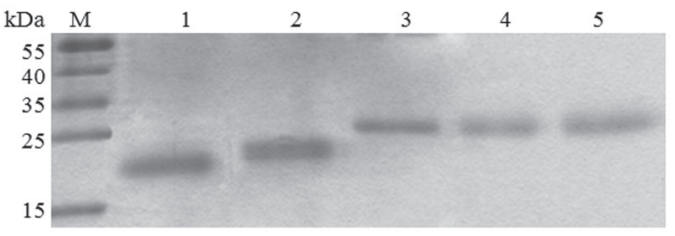

B

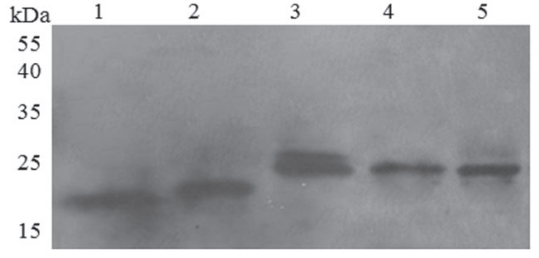

$\mathrm{D}$

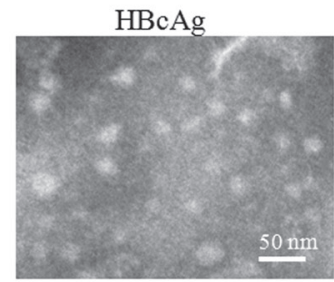

$\mathrm{HBcAg} / \mathrm{Ct}-\mathrm{MOMP}_{370-387}$

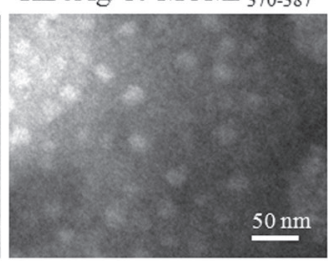

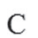

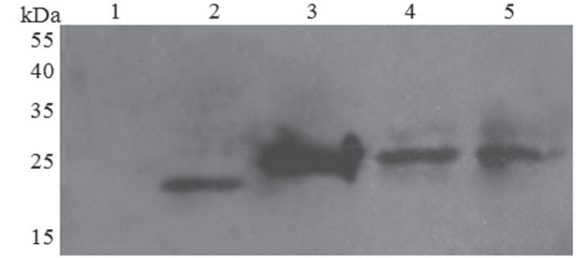

$\mathrm{HBcAg} / \mathrm{Th} / \mathrm{Ct}$ MOMP $_{370-387}$

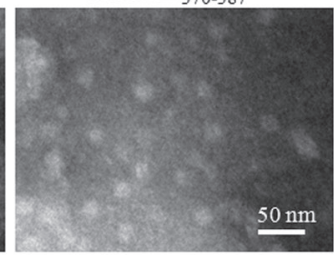

$\mathrm{Th} / \mathrm{Ct}-\mathrm{MOMP}_{370-}$ ${ }_{387} / \mathrm{HBcAg}$

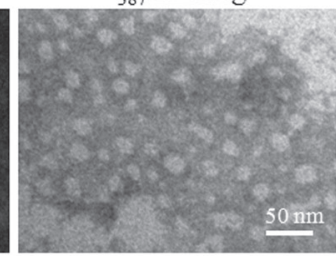

$\mathrm{HBcAg}-\mathrm{MIR} / \mathrm{Th} / \mathrm{Ct}$ $\mathrm{MOMP}_{370-387}$

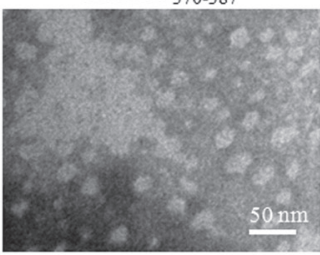

Figure 2: Expression of recombinant proteins and formation of HBcAg/MOMPm chimeric VLPs. A. Comassie bluestained SDS-PAGE gel of the purified recombinant proteins. B. Western blot analysis of recombinant proteins with anti-HBcAg antibody. C. Western blot analysis of recombinant proteins with anti-Ct antibody. In western blot analysis, SDS-PAGE gels were run under the same experimental conditions in section A. Then, proteins were transferred to a polyvinylidene fluoride membrane for western blot analysis with indicated antibodies. $\mathrm{M}$, protein marker; 1, the purified recombinant $\mathrm{HBcAg}$ protein; 2, the purified recombinant $\mathrm{HBcAg} / \mathrm{Ct}$ - $\mathrm{MOMP}{ }_{370-387}$ protein; 3, the purified recombinant $\mathrm{HBcAg} / \mathrm{Th} / C t-\mathrm{MOMP}_{370-387}$ protein; 4, the purified recombinant $\mathrm{Th} / \mathrm{Ct}-\mathrm{MOMP}$ 370-387 $/ \mathrm{HBcAg}$ protein; 5, the purified recombinant $\mathrm{HBcAg}-\mathrm{MIR} / \mathrm{Th} / \mathrm{Ct}$-MOMP ${ }_{370-387}$ protein. D. The formation of HBcAg/MOMPm chimeric VLPs observed by negative-stain electron microscopic analysis. 


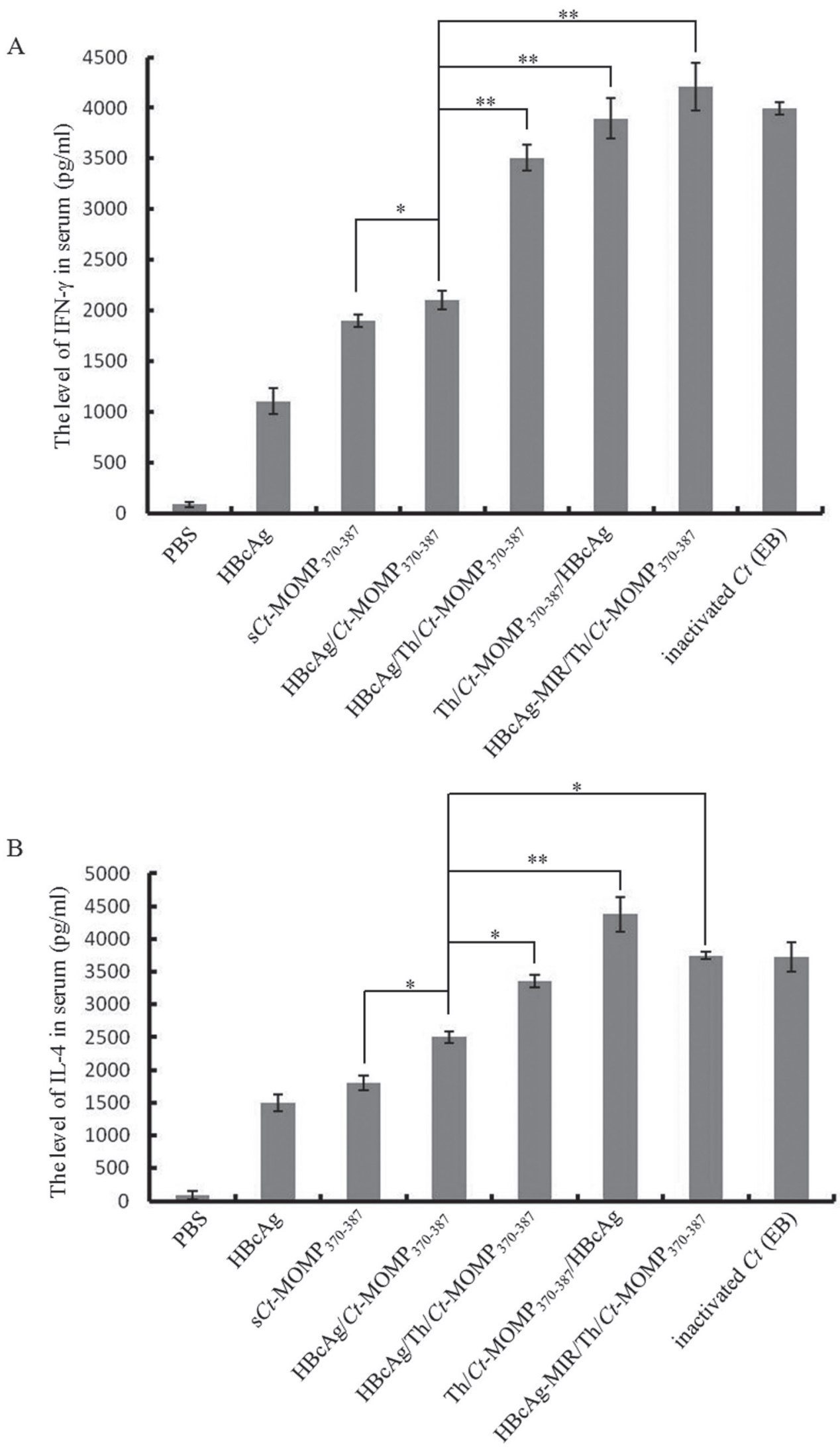

Figure 3: The levels of cytokines in the serum of mice immunized with different agents. A. The level of IFN- $\gamma$ in the serum. B. The level of IL-4 in the serum. All experiments were performed in triplicate and data are expressed as means $\pm \mathrm{SD}(n=3)$. Error bars represent standard deviations of replicate data points. ${ }^{*} p<0.05,{ }^{* *} p<0.01$ between two indicated groups. 
immunized mice was further analyzed by CTL assay. As shown in Figure 5, at any of effector/target cell (E/T) ratio, splenic lymphocytes derived from mice of test and positive groups exhibited significantly higher cytotoxicity than negative control groups (PBS and $\mathrm{HBcAg}$ ). Meanwhile, splenic lymphocytes from the group of $\mathrm{Th} /$ Ct-MOMP ${ }_{370-387} / \mathrm{HBcAg}$ exhibited the highest cytotoxicity at the effector/target ratio of 20:1 and 40:1.

\section{Protective immunity induced by HBcAg/MOMPm chimeric VLPs}

Protective efficacy was evaluated by challenging the mice with $10^{6}$ inclusion-forming units (IFUs) $C t$ via the intra-vaginal route at week 8 . Protection was assessed by isolation of $C t$ from vaginal swabs and comparing the number of IFUs recovered from immunized mice at the indicated time points. As shown in Figure 6A, compared with mice in negative control groups, mice in five test groups were highly resistant to infection (as indicated by the lower IFU number and the shorter time to resolution of the infection). Except the positive control group, the most significant level of protection was observed in mice immunized with $\mathrm{Th} / \mathrm{Ct}$-MOMP${ }_{370-387} / \mathrm{HBcAg}$, followed by mice immunized with $\mathrm{HBcAg} / \mathrm{Th} / \mathrm{Ct}-\mathrm{MOMP}_{370-387}$ and $\mathrm{HBcAg} / \mathrm{Ct}-\mathrm{MOMP}_{370-387}$, respectively. All mice immunized with $\mathrm{HBcAg} / \mathrm{MOMPm}$ chimeric VLPs showed complete resolution of the infection within 24 days after the initial challenge except those immunized with $\mathrm{HBcAg-MIR/}$ $\mathrm{Th} / C t$-MOMP ${ }_{370-387}$. These results indicate that $\mathrm{HBcAg}$ as a carrier for $C t$ MOMPm peptide enhances protection

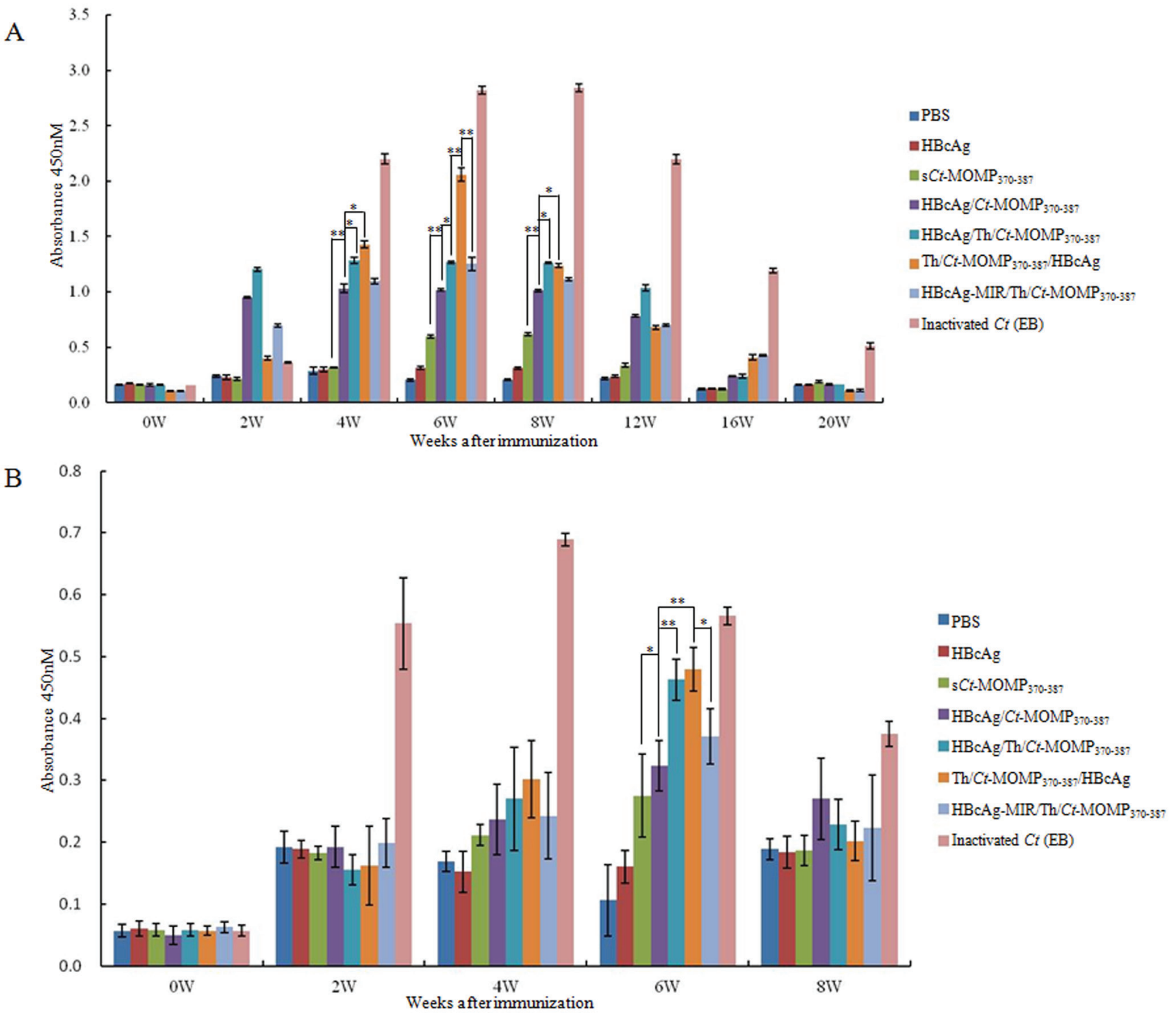

Figure 4: The levels of antibodies in the mice immunized with different agents. The levels of $C t$-specific serum IgG A. and secretory IgA B. were analyzed by ELISA. All experiments were performed in triplicate and data are expressed as means $\pm \operatorname{SD}(n=3)$. Error bars represent standard deviations of replicate data points. ${ }^{*} p<0.05,{ }^{*} p<0.01$ between two indicated groups. 


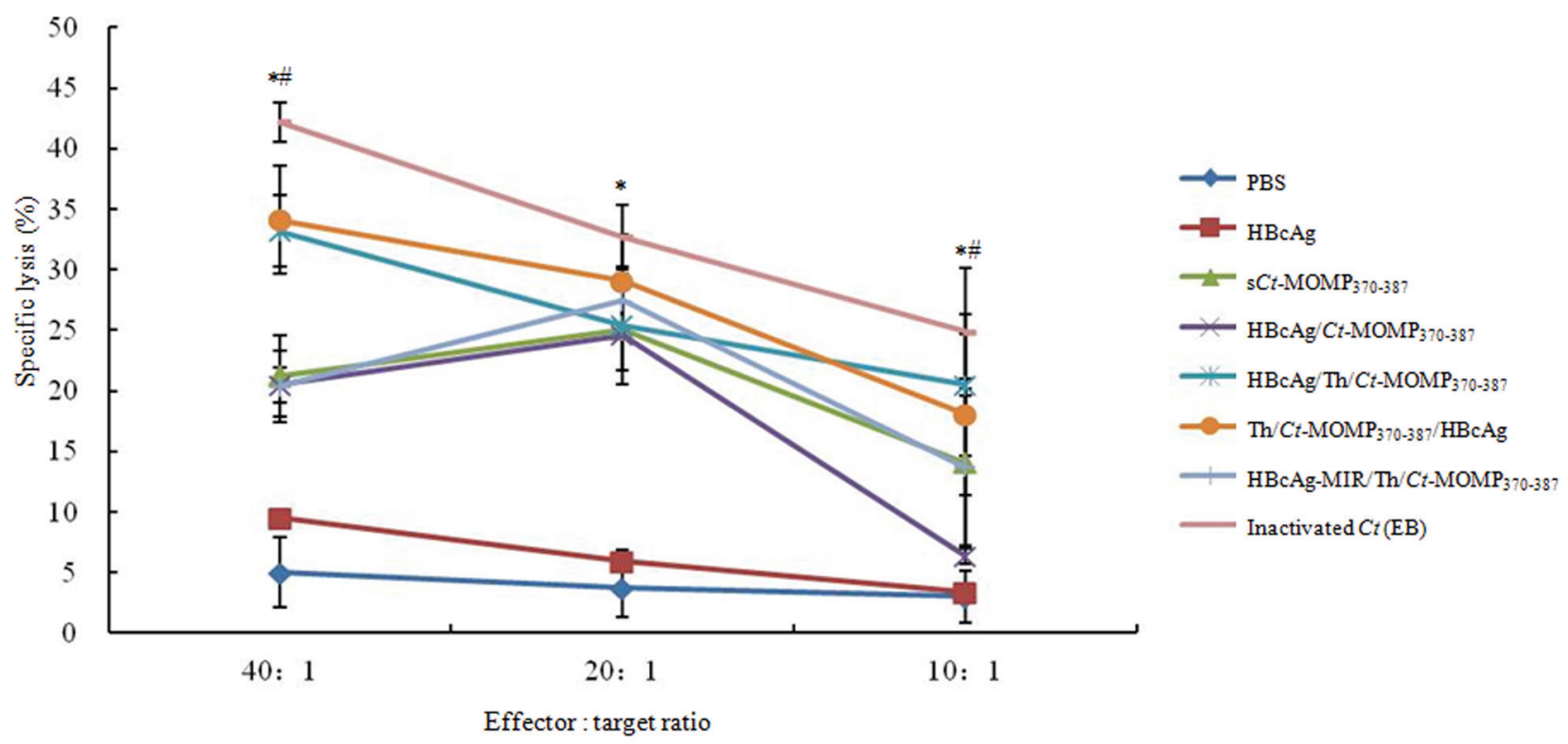

Figure 5: The CTL response of splenic lymphocytes against $C t$ in mice immunized with different agents was analyzed by a standard LDH assay. Splenic lymphocytes derived from mice of test groups ( $\mathrm{sCt}$-MOMP${ }_{370-387}, \mathrm{HBcAg} / \mathrm{Ct}-\mathrm{MOMP}{ }_{370-387}, \mathrm{HBcAg} /$ $\mathrm{Th} / \mathrm{Ct}$-MOMP ${ }_{370-387}, \mathrm{Th} / \mathrm{Ct}$-MOMP $370-387 \mathrm{HBcAg}$, and $\mathrm{HBcAg}-\mathrm{MIR} / \mathrm{Th} / C t$-MOMP $\left.{ }_{370-387}\right)$ exhibited significantly higher cytotoxicity than those from negative control groups (PBS and $\mathrm{HBcAg})\left({ }^{*} p<0.05\right)$ at any of effector/target cell ratio. Splenic lymphocytes from the group of $\mathrm{Th} / \mathrm{Ct}$-MOMP ${ }_{370-387} / \mathrm{HBcAg}$ exhibited the highest cytotoxicity at the effector/target ratio of 20:1 and 40:1 (\#p<0.05). All experiments were performed in triplicate and data are expressed as means $\pm \mathrm{SD}(n=3)$. Error bars represent standard deviations of replicate data points.
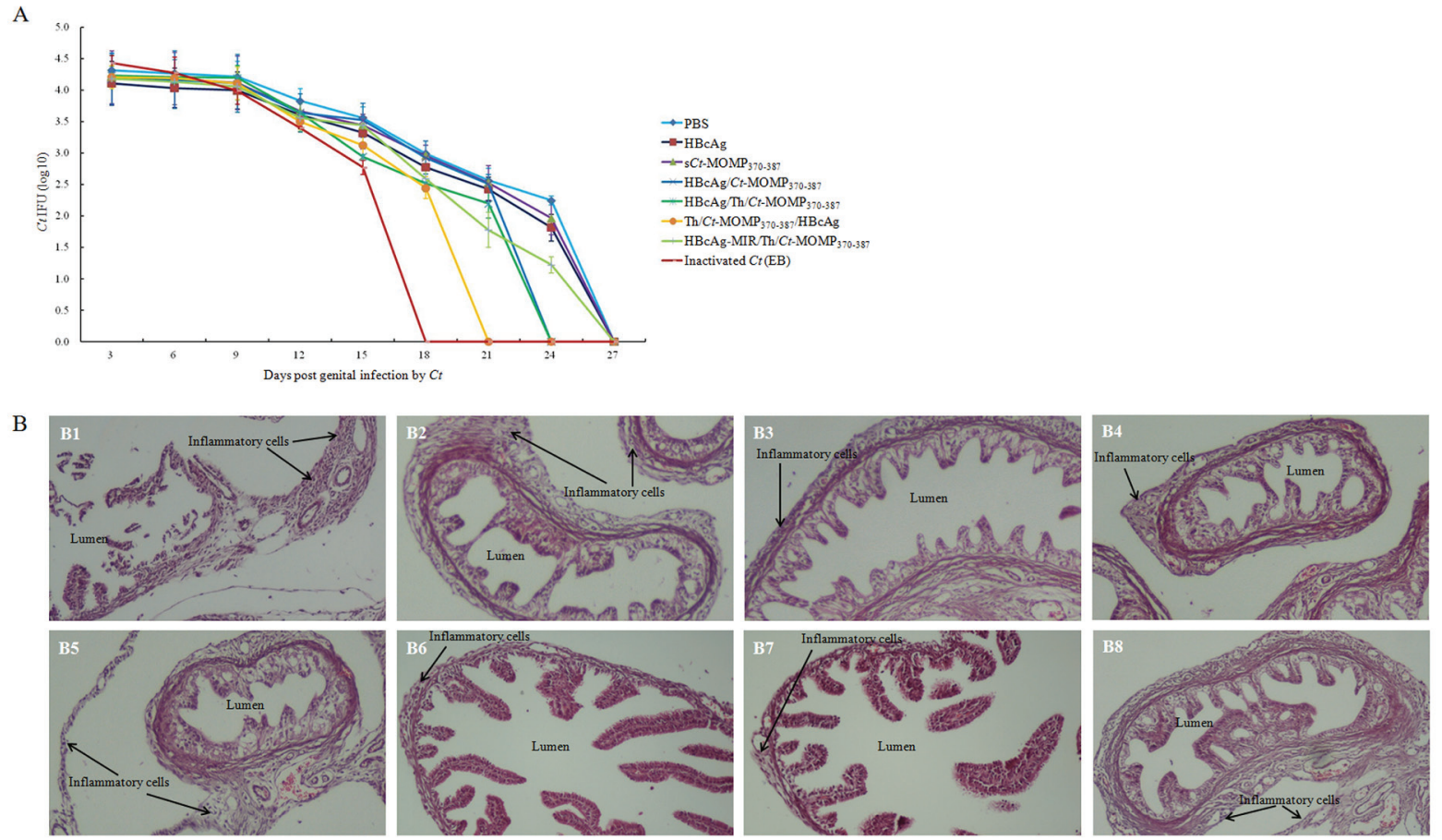

Figure 6: Immunization with HBcAg/MOMPm chimeric VLPs protects mice against $C t$ infection. A. $C t$ shedding (IFUs) was measured from vaginal swabs every 3 days post challenge. The mice in five test groups were highly resistant to infection (as indicated by the lower IFU number and the shorter time to resolution of the infection) compared with mice in negative control groups. B. The effect of immunization with $\mathrm{HBcAg} / \mathrm{MOMPm}$ chimeric VLPs on inflammatory pathologies in mouse upper genital tract. Thirty days after chlamydial infection, mice were sacrificed for pathology observation. The genital tract tissues were sectioned for microscopic observation of inflammatory pathologies. Representative $\mathrm{H} \& \mathrm{E}$ stained section images from each group of mice genital tracts tissue (original magnification, $\times 100$ ) were shown. The location of lumen and examples of inflammatory cell infiltration were indicated. B1, PBS; B2, $\mathrm{HBcAg}$; B3, sCt-MOMP ${ }_{370-387} ; \mathrm{B} 4, \mathrm{HBcAg} / \mathrm{Ct}-\mathrm{MOMP}_{370-387} ; \mathrm{B} 5, \mathrm{HBcAg} / \mathrm{Th} / \mathrm{Ct}-\mathrm{MOMP}_{370-387} ; \mathrm{B} 6, \mathrm{Th} / \mathrm{Ct}$-MOMP ${ }_{370-387} / \mathrm{HBcAg} ; \mathrm{B} 7, \mathrm{HBcAg}-$ $\mathrm{MIR} / \mathrm{Th} / \mathrm{Ct}$-MOMP ${ }_{370-387} ; \mathrm{B} 8$, inactivated $C t(\mathrm{~EB})$. Note that immunization with $\mathrm{HBcAg} / \mathrm{MOMPm}$ chimeric VLPs significantly reduced both lumen dilatation and inflammatory cell infiltration. 
against genital chlamydial infection.

We further evaluated the effect of immunization with $\mathrm{HBcAg} / \mathrm{MOMPm}$ chimeric VLPs on inflammatory pathologies in mouse upper genital tract. Thirty days after the intra-vaginal challenge infection, mice were sacrificed and mouse genital tract tissues were collected for pathology evaluation. As shown in the results of histology (Figure 6B), the mice immunized with inactivated $C t$ (EB) showed nearly normal oviduct lumens and only scattered inflammatory cells in oviduct tissues. The mice immunized with $\mathrm{HBcAg} / \mathrm{MOMPm}$ chimeric VLPs exhibited milder luminal dilatation and inflammatory cell infiltration. However, highly dilated oviduct lumens and extensive inflammatory infiltration were observed in the oviduct tissues of mice immunized with sCt-MOMP ${ }_{370-387}$, $\mathrm{HBcAg}$ or PBS. Furthermore, some of the fallopian tubal folds were even disappeared in the tissues of negative control groups.

The above results demonstrated that the immunity induced by MOMPm could shorten the time course of live organism shedding and reduce the inflammatory damages in the mouse oviducts. Therefore, a chimeric vaccine based on the HBcAg platform has significant advantages in protecting vaccinated recipients from chlamydial infection.

\section{DISCUSSION}

Currently, selection of appropriate target antigens is the main problem in the development of $C t$ vaccine [15]. Although killed vaccines offer some degree of protection, they can lead to detrimental side effects [16]. MOMP is crucial to chlamydial infection and pathogenesis due to its interaction with host proteins and inhibition of phagosomelysosome fusion [17]. Owing to its immunogenicity, MOMP has been widely used as a candidate antigen to develop a vaccine against chlamydial infection [18-20]. However, it is difficult to obtain recombinant MOMP in a native form with intact, conformationally relevant epitopes due to its cysteine-rich structure. Therefore, MOMPm epitopes ( $\mathrm{T}$ - and B-cell epitope-rich peptide clusters) have recently been designed as the immunogen in order to induce a cellular and humoral immune synergetic effect $[21,22]$.

Multi-epitope vaccine could not only solve problems of immunodominance but also generate broad immune response [23, 24]. However, multi-epitope vaccine needs a suitable antigen delivery and release vehicle to stimulate effective immune response. Several carrier systems have been used to develop $\mathrm{Ct}$ vaccines such as viral or bacterial ghosts, cytokine fusion constructs, $\mathrm{CpG}$ lipophilic ISCOMs, dendritic cell, and VLPs [22, 25-28].

VLPs preserve the native antigenic conformation of the immunogenic proteins without any risks of infection and thus offer unique advantages in terms of safety and immunogenicity over other vaccine carrier systems $[29$,
30]. As reported in our previous studies, using hepatitis $B$ virus surface antigen and human papillomavirus major capsid protein L1 as delivery vectors for $C t$ MOMPm DNA vaccines could induce protective immunity against $C t$ infection [21, 22]. However, DNA vaccines still have some disadvantages, such as their weak immunogenicity and the lack of efficient DNA delivery platforms (reviewed in $[31,32])$. HBcAg that has been used as vaccine carrier systems for almost three decades holds a unique position among VLP carriers because of its high-level expression and efficient particle formation in virtually all known expression systems [8, 9]. Therefore, in this study, $\mathrm{HBcAg}$ was used as a delivery system for $C t$ MOMPm. We analyzed the efficacy of the novel HBcAg/MOMPm chimeric vaccine. The results of SDS-PAGE and western blot analysis showed that the $\mathrm{HBcAg}$ fused proteins were effectively expressed and these proteins also formed VLPs successfully as expected (Figure 2).

The $C t$ MOMPm designed in this study not only contains HLA-A*02:01, HLA-A*11:01, HLADRB1*0401, and HLA-A*24:02 restricted T-cell epitopes and a reported B-cell epitope but also contains mouse H2$\mathrm{Kd}$ restricted CTL epitopes (Figure 1) in order to evaluate the immune response on murine model.

Lymphocyte homeostasis is required to maintain the normal immune function [33]. CD4 ${ }^{+}$T-cells, an important kind of lymphocytes, can be divided into Th1 and Th2 cells according to different cytokine secretion. Th1 cells mainly produce IFN- $\gamma$ and IL-2, which are critical to cellular immunity and CTL responses, whereas Th2 cells mainly produce IL-4 and IL-10, which enhance antibody production by B cells and improve humoral immunity [34]. The result of our cytokine assay showed that immunization with $\mathrm{HBcAg} / \mathrm{Ct}-\mathrm{MOMP}_{370-387}$ and $\mathrm{HBcAg} /$ $\mathrm{Th} / C t$ MOMP $_{370-387}$ both resulted in significantly higher level expression of IFN- $\gamma$ and IL-4 compared with the group of sCt-MOMP ${ }_{370-387}$ and negative groups (Figure 3), according to which we speculated that immunization with $\mathrm{HBcAg} / \mathrm{Ct}-\mathrm{MOMP}_{370-387}$ and $\mathrm{HBcAg} / \mathrm{Th} / \mathrm{Ct}-\mathrm{MOMP}_{370-387}$ could induce both humoral and cellular immune responses. Interestingly, this hypothesis was confirmed by detection of $C t$-specific serum IgG and secretory IgA and CTL assay. As shown in Figure 4A and 4B, higher levels of $\mathrm{IgG}$ and $\operatorname{sIgA}$ were induced in groups of $\mathrm{HBcAg} / \mathrm{Ct}$ $\mathrm{MOMP}_{370-387}$ and $\mathrm{HBcAg} / \mathrm{Th} / \mathrm{Ct}-\mathrm{MOMP}_{370-387}$ than that in group of sCt-MOMP ${ }_{370-387}$. Similar results were obtained in CTL assay (Figure 5). These results indicate that $\mathrm{HBcAg}$ is also an excellent carrier for development of the $C t \mathrm{MOMPm}$ vaccine and that Th epitope can enhance the immunogenicity of the $C t$ MOMPm. In addition, as shown in Figure 3, Figure 4 and Figure 5, the $\mathrm{N}$-terminus fusion $\left(\mathrm{Th} / \mathrm{Ct}\right.$-MOMP ${ }_{370-387} / \mathrm{HBcAg}$ ) exhibited the best immunogenicity in the three ways that $C t$ MOMPm was fused with $\mathrm{HBcAg}$, which was inconsistent with previous studies $[9,35]$. In those studies, the MIR of $\mathrm{HBcAg}$ is the preferable insertion site for foreign proteins. There 
may be at least two reasons for the difference between our results and previous studies. The first one is the different lengths of foreign proteins and the second one is the different insertion sites of Th epitope. Further studies need to be done to characterize the mechanism of the best immunogenicity by N-terminus fusion of foreign proteins to $\mathrm{HBcAg}$ in our results.

We also investigated the ability of the $\mathrm{HBcAg} /$ MOMPm chimeric VLPs to induce protective immunity. As shown in Figure 6A and 6B, mice immunized with the $\mathrm{HBcAg} / \mathrm{Ct}$-MOMP ${ }_{370-387}$ and $\mathrm{HBcAg} / \mathrm{Th} / \mathrm{Ct}-\mathrm{MOMP}_{370-387}$ both induced protection against genital chlamydial infection. Furthermore, immunization with $\mathrm{HBcAg} / \mathrm{Th} / \mathrm{Ct}$ MOMP $_{370-387}$ induced more significant level of protection. These results indicate that $\mathrm{HBcAg}$ as a carrier for $C t$ MOMPm peptide significantly enhances protection against genital chlamydial infection and that the Th epitope also enhances this protection. Additionally, MOMPm fused to different insertion sites (C-terminus, N-terminus or MIR) of $\mathrm{HBcAg}$ exhibited different levels of protection against $C t$ challenging and the best way was $\mathrm{N}$-terminus fusion, which was generally consistent with the results of immunogenicity assay.

Taken together, our results support the notion that vaccines based on chimeric $\mathrm{HBcAg}$ carrying $C t \mathrm{MOMPm}$ could be an effective immune prophylactic for chlamydial infection in murine model system and that different ways of $C t$ MOMPm fused with $\mathrm{HBcAg}$ could induce different levels of protective immune response against genital chlamydial infection. Therefore, our results could be useful for the development of vaccines to protect human beings against chlamydial infection.

\section{MATERIALS AND METHODS}

\section{Ethics statement}

Our study had been approved by Animal Care and Use Committee of Zhejiang Province, China. All animal procedures were performed according to guidelines developed by the China Council on Animal Care and protocol approved by Animal Care and Use Committee of Zhejiang Province, China.

\section{Chlamydial organisms and reagents}

$C t$ serovar E organisms (ATCC VR-348B) were grown, purified, and titrated as previously described [36]. Samples with chlamydial infection in various assays were prepared as previously described [21]. Polyclonal rabbit IgG antibody against $C t$ were prepared by immunizing rabbits with inactivated $C t(\mathrm{~EB})$ in our laboratory. Mouse monoclonal antibody against $\mathrm{HBcAg}$ was purchased from Abcam $^{\circledR}$. Horseradish peroxidase (HRP)-labeled goat anti- rabbit and goat anti-mouse secondary antibodies were also purchased from $\mathrm{Abcam}^{\circledR}$.

\section{Screening and generating Ct MOMPm}

Multi-epitope peptide was screened as following. Briefly, the amino acid sequence of MOMP from $C t$ serovar E (http://www.uniprot.org/uniprot/P17451) was obtained from the Swiss-prot database (http://www. expasy.org/sprot/), which was analyzed using SYFPEITHI program (http://www.syfpeithi.de/bin/MHCServer.dll/ EpitopePrediction.htm) to predict both HLA and $\mathrm{H} 2$ restricted CTL epitopes. The peptide $\left(\mathrm{MOMP}_{370-387}\right)$ with high score containing the reported B-cell epitope (TRLIDERAAH) [13] was selected to be a candidate for MOMPm, according to which the nucleic acids of MOMPm were synthesized.

\section{Constructing the HBcAg/MOMPm plasmid}

HBcAg gene was amplified by polymerase chain reaction (PCR) from the serum of $\mathrm{HBV}$ carriers with standard protocols using the following primer pair: forward, 5'-ATGCAACTTTTTCACCTCTGCCTAAT-3' and reverse, 5'-CTAACATTGAGATTCCCGAGATTGAGA-3'.

The amino acid sequence encoded by our $\mathrm{HBcAg}$ gene was consisted with that retrieved in NCBI (GenBank ID: X01587). Then, HBcAg gene with 6 His-tags at the N-terminus was amplified using the following primer pair: forward, 5' - GGAATTCCATATGCAC CATCATCATCATCATGACATTGACCCGTATAAAG 3' and reverse, 5'-GGGGTACCACATTGAGATTCCCG-3' and subcloned into the $\mathrm{pET} 32 \mathrm{a}(+)$ vector between restriction endonucleases sites of Nde I and Kpn I (named as pET32a(+)/HBcAg). The pET32a(+)/HBcAg vector was digested by double restriction endonucleases at the sites of Nde I and EcoRI and the shorter nucleic acids was subcloned into the corresponding sites of $\mathrm{pET} 21 \mathrm{a}(+)$ vector (named as pET21a(+)/HBcAg). The nucleic acids of MOMPm with KpnI and BamHI restriction endonucleases sites were synthesized (forward, 5' - CAAATACGCTGTTACCGTTGAAA CCCGTCTGATCGACG

AACGTGCTGCTCACGTTG - 3' and reverse, 5' GATCCAACGTGAGCAGCACGTTCGTCGATCAG ACGGGTTTCAA CGGTAACAGCGTATTTGGTAC - 3') and subcloned into the corresponding sites of pET21a(+)/HBcAg vector (named as pET21a $(+) /$ $\mathrm{HBcAg} / \mathrm{Ct}-\mathrm{MOMP}_{370-387}$ ). To enhance the immunogenicity of MOMPm, the nucleic acids of universal helper T-lymphocyte epitope (Th epitope, PADRE) [37-39] with KpnI and BamHI restriction endonucleases sites (forward, 5, - CGCTAAAT TCGTTGCTGCTTGGACCC TGAAAGCTGCTGCTG 
- 3' and reverse, 5' - GATCCAGCAGCAGCTTT CAGGGTCCAAGCAGCAACGAATTTAGCGGTAC

- 3') and the nucleic acids of mMOMP $_{370-387}$ epitope with BamHI and HindIII restriction endonucleases sites (forward, 5' GATCCAAATACGCTGTTACCGTTGAAACCCGT CTGATCGACGAACGTGCTGCTCACGTTA - 3' and reverse, 5' AGCTTCTAAACGTGAGCAGCACGTTCGTCGATCA GACGGGTTTCAACGGTAACAGCGTATTTG - 3') were respectively synthesized and subcloned into the pET21a(+)/HBcAg vector between restriction endonucleases sites KpnI and HindIII (named as pET21a $\left.(+) / \mathrm{HBcAg} / \mathrm{Th} / \mathrm{Ct}-\mathrm{MOMP}_{370-387}\right)$. The nucleic acids of Th epitope and mMOMP m70-387 epitope with two NdeI restriction endonucleases sites (forward, 5' TATGGCTAAATTCGTTGCTGCTTGGACCCTGAAA GCTGCTGCTGGATCCAAATACGCTG

TTACCGTTGAAACCCGTCTGA

TCGACGAACGTGCTGCTCACG TTCA - 3' and reverse, 5' - TATGAA CGTGAGC AGCACG TTCGTCGATCAGACGGGTTT CAACGGTAACAGCG TATTT GGATCCAGCAGCAGCT TTCA GGGTCCAA GCAGCAACGAATTTAGCCA - 3') were synthesized and subcloned into the corresponding sites of pET21a(+)/ $\mathrm{HBcAg}$ vector (named as pET21a(+)/Th/Ct-MOMP ${ }_{370-387} /$ $\mathrm{HBcAg}$ ). The nucleic acids of mutant $\mathrm{HBcAg}$ gene (restriction endonuclease sites of BamHI and SacI were generated by synonymous mutation at amino acid site of 74 and 82 because MIR was located in this region) with Th epitope were synthesized and subcloned into the pET21a $(+)$ vector between restriction endonucleases sites NdeI and HindIII (named as pET21a(+)/HBcAg-MIR). Then, the nucleic acids of $\mathrm{mMOMP}_{370-387}$ epitope with BamHI and SacI restriction endonucleases sites (forward, 5'-GATCCAAATACGCTGTTACCGTTGAAACCCG TCTGAT CGACGAACGTGCTGCTCACGTTGAGCT 3' and reverse, 5'-CAACGTGAGCAGCACGTTCGTCGA TCA GACGGGTTTCAACGGTAACAGCGTATTTG 3 ') were synthesized and subcloned into the corresponding sites of pET21a(+)/HBcAg-MIR vector (named as

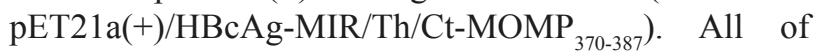
the recombinant vectors were confirmed by restriction endonuclease digestion and sequencing.

\section{Preparing HBcAg/MOMPm chimeric VLPs}

E. coli Rosseta (DE3) was transformed with three kinds of recombinant vectors respectively and induced by IPTG $(0.8 \mathrm{mmol} / \mathrm{L})$ to express corresponding recombinant proteins with 6 His-tags including $\mathrm{HBcAg}$, $\mathrm{HBcAg} / \mathrm{Ct}$-MOMP ${ }_{370-387}, \quad \mathrm{HBcAg} / \mathrm{Th} / \mathrm{Ct}-\mathrm{MOMP}_{370-387}$, $\mathrm{Th} / \mathrm{Ct}$-MOMP ${ }_{370-387} / \mathrm{HBcAg}$ and $\mathrm{HBcAg}-\mathrm{MIR} / \mathrm{Th} / \mathrm{Ct}-$ MOMP $_{370-387}$. Purification of HBcAg VLPs and $\mathrm{HBcAg} /$ MOMPm chimeric VLPs was performed as described in previous studies with minor modifications [40, 41].
Briefly, the recombinant proteins were adjusted to dissociation buffer ( $6 \mathrm{M}$ urea, $10 \mathrm{mM}$ imidazole, $50 \mathrm{mM}$ sodium phosphate buffer, $\mathrm{pH} 8.0$, and $50 \mathrm{mM} \mathrm{NaCl}$ ), and incubated at $37{ }^{\circ} \mathrm{C}$ for $30 \mathrm{~min}$; all subsequent steps were performed at room temperature. The solutions were mixed at the desired molar ratios, and bound to a $\mathrm{Ni}^{2+}$ nitrilotriacetic acid $\left(\mathrm{Ni}^{2+}-\mathrm{NTA}\right)$ column pre-equilibrated in dissociation buffer (usually $1-2 \mathrm{ml}$ protein solution for a $2 \mathrm{ml}$ gel bed column). The urea concentration was decreased by washing with $2 \mathrm{ml}$ each of washing buffer (20 mM imidazole, $50 \mathrm{mM}$ sodium phosphate, $\mathrm{pH} 8.0$, and $50 \mathrm{mM} \mathrm{NaCl}$ ) containing $5,4,3,2,1$ and $0.5 \mathrm{M}$ urea, followed by pure washing buffer, then washing buffer containing $300 \mathrm{mM} \mathrm{NaCl}$. Finally, twice the gel bed volume of elution buffer $(250 \mathrm{mM}$ imidazole, $50 \mathrm{mM}$ sodium phosphate buffer, $\mathrm{pH} 8.0$, and $300 \mathrm{mM} \mathrm{NaCl}$ ) was added. After $1 \mathrm{~h}$ incubation, the proteins were eluted by gravity flow. To separate CLPs from non-assembled forms, dialyzed and concentrated samples were subjected to sedimentation in $10-60 \%(\mathrm{wt} / \mathrm{vol})$ sucrose density gradient ultracentrifugation. The purified proteins were confirmed by western blot analysis and the reassembled VLPs were observed by negative-stain electron microscopic analysis.

\section{Western blot}

The recombinant proteins were separated by SDS-PAGE and then transferred to a polyvinylidene fluoride membrane (Millipore, Billerica, MA, USA). The membrane was blocked with blocking buffer (5 $\%$ skimmed milk in Tris-HCl buffered saline) and then incubated with indicated primary antibodies over night at $4{ }^{\circ} \mathrm{C}$, followed by HRP-conjugated secondary antibodies at room temperature for $1 \mathrm{~h}$. The protein bands were visualized by Luminata Classico Western HRP Substrate as per the manufacturer's instructions (Millipore, Billerica, MA, USA).

\section{Negative-stain transmission electron microscopy}

Particle preparations were spotted onto carboncoated copper grids and negatively stained with $3 \%(\mathrm{w} / \mathrm{v})$ phosphotungstic acid. The grids were examined using an FEI Tecnai 20 transmission electron microscope operating at $200 \mathrm{kV}$.

\section{Analyzing the immunogenicity of $\mathrm{HBcAg} /$ MOMPm chimeric VLPs}

A total of $40 \mathrm{BALB} / \mathrm{c}$ female mice $(\mathrm{H} 2-\mathrm{Kd})$ at the age of 6 to 8 weeks old were purchased from Shanghai Experimental Animal Center at the Chinese Academy of Sciences and randomly divided into 8 groups. The mice of each group were randomly assigned to receive 
immunization with PBS, HBcAg, sCt-MOMP ${ }_{370-387}$, $\mathrm{HBcAg} / C t$-MOMP ${ }_{370-387}, \mathrm{HBcAg} / \mathrm{Th} / C t-\mathrm{MOMP}_{370-387}, \mathrm{Th} /$ $C t$-MOMP ${ }_{370-387} / \mathrm{HBcAg}, \mathrm{HBcAg}-\mathrm{MIR} / \mathrm{Th} / C t$-MOMP ${ }_{370-387}$ and inactivated $C t$ (EB). Each mouse was immunized with $100 \mu \mathrm{l}$ indicated samples (dissolved in PBS, $1 \mathrm{mg}$ / $\mathrm{ml}$ ) by subcutaneous injection at the first day of week 0 , 2,4 . The tail blood was respectively collected at the last day of week $0,2,4,6,8,10,12,14,16,18$, and 20 and the vaginal washes were respectively collected at the last day of week $0,2,4,6$, and 8 . Then, indirect ELISA was performed to detect $C t$-specific serum IgG and secretory IgA. Another 40 mice were also divided into 8 groups and immunized as mentioned above to perform CTL assay. The mouse splenic lymphocytes were isolated for CTL assay at the last day of week 7 .

\section{Determination of $C t$-specific serum IgG and secretory IgA}

Microplates were coated with purified whole $C t$ protein (BestBio biotechnology co. Shanghai, China). After incubation at $4{ }^{\circ} \mathrm{C}$ overnight, the plates were rinsed with PBS solution containing $0.05 \%$ Tween 20 (PBST). The coated plates were blocked with $100 \mu$ l blocking buffer (5\% skimmed milk in PBST) at $37{ }^{\circ} \mathrm{C}$ for $1 \mathrm{~h}$. After being rinsed for 5 times with PBST, the plates were incubated with immune sera (diluted at 1:1000 in blocking buffer, $100 \mu \mathrm{l} /$ well) or vaginal washes (diluted at 1:10 in blocking buffer, $100 \mu \mathrm{l} /$ well) at $37^{\circ} \mathrm{C}$ for $2 \mathrm{~h}$. After being rinsed for 5 times with PBST, the plates were incubated with HRP-conjugated goat anti-mouse IgG antibody (diluted at 1:1000 in blocking buffer, $100 \mu \mathrm{l} /$ well) or HRP-conjugated goat anti-mouse sIgA antibody (diluted at 1:2000 in blocking buffer, $100 \mu \mathrm{l} /$ well) at $37^{\circ} \mathrm{C}$ for $1 \mathrm{~h}$. After being rinsed again, the plates were incubated with 3, 3', 5, 5'-tetramethylbenzidine (TMB) $-\mathrm{H}_{2} \mathrm{O}_{2}$ solution (100 $\mu \mathrm{l} /$ well) at room temperature for $20 \mathrm{~min}$ and then with $2 \mathrm{~mol} / \mathrm{L} \mathrm{H}_{2} \mathrm{SO}_{4}(50 \mu \mathrm{l} /$ well $)$ to stop the reaction. The resultant color was measured at $450 \mathrm{~nm}$ in a Bio-tek ELISA microplate reader.

\section{Cytokine assay}

The levels of interferon (IFN)- $\gamma$ (a classical Th1derived cytokine) and interleukin (IL)-4 (a classical Th2derived cytokine) in the serum of mice from different groups at week 8 were measured using commercially available ELISA cytokine kits (eBioscience, USA) as per the manufacturer's protocol.

\section{CTL assay}

Short-term CTL cultures were generated as previously described with some modifications [42, 43].
Briefly, at week 7, splenic lymphocytes were collected from immunized mice as the effector cells, $5 \times 10^{6}$ of which were co-cultured with $2 \times 10^{5}$ inactivated $C t$ (EB) in presence of $0.5 \mathrm{ng} / \mathrm{ml} \mathrm{IL-7} \mathrm{and} \mathrm{20U/ml} \mathrm{IL-2} \mathrm{for} 5$ days in 24-well tissue culture plates. The cytolytic activity of the cultures was determined using a lactate dehydrogenase (LDH) release assay kit (Promega, Wisconsin, USA). The target cells, Chlamydia-infected BALB/3T3 cells, were dispensed into 96-well round-bottom plates $\left(10^{4}\right.$ cells/ well) and then serial dilutions of effector cells were added to the wells. The plates were centrifuged at $1500 \mathrm{rpm}$ for $10 \mathrm{~min}$. After $4 \mathrm{~h}$, the plates were centrifuged again. $50 \mu \mathrm{l}$ supernatant was transferred to another plate and mixed with the substrate mix provided in the test kits. The reaction was stopped after $30 \mathrm{~min}$ and read using a Biotek ELISA microplate reader at a wave-length of $490 \mathrm{~nm}$. Specific lysis was determined as follows: \% specific lysis $=100 \times[($ release in the presence of CTL - spontaneous release) / (maximal release spontaneous release)]. In all experiments, the spontaneous release was less than $30 \%$ of the maximal release.

\section{Evaluating the protective effect of $\mathrm{HBcAg} /$ MOMPm chimeric VLPs against genital chlamydial infection in mice}

Eight groups of mice (5 mice/group) were immunized as described above. At week 8 , the mice were challenged intra-vaginally with $10^{6}$ IFUs of live $C t$ serovar E. Five days prior to infection, each mouse was injected with $2.5 \mathrm{mg}$ Depo-provera (Pharmacia Upjohn, Kalamazoo, MI, USA) subcutaneously to synchronize menstrual cycle and increase mouse susceptibility to chlamydial infection. The protective effect was assessed by calculating the isolation of Chlamydia from vaginal swabs. Vaginal swabs were obtained once every 3 days after the intra-vaginal infection until two consecutive negative detection results were obtained from the same mouse. Thirty days after chlamydial infection, the reproductive tract was dissected and histopathological comparisons among mice from the 8 groups were then performed. Both the inflammatory cell infiltration and luminal dilatation were evaluated by double-blind examiner.

\section{Statistical analysis}

ANOVA test was performed to analyze data from multiple groups and a two-tailed Student $t$ test to compare the means between two groups. A chi-squared test was used for comparing the rate of incidence between two groups. The level of significance was set at $p<0.05$.

\section{CONFLICTS OF INTEREST}

There is no conflict of interest among the authors. 


\section{FUNDING}

This work was supported by the grant from the National Natural Science Foundation of China (Grant No. 30972669).

\section{REFERENCES}

1. Miller WC, Ford CA, Morris M, Handcock MS, Schmitz JL, Hobbs MM, Cohen MS, Harris KM and Udry JR. Prevalence of chlamydial and gonococcal infections among young adults in the United States. JAMA. 2004; 291:22292236.

2. Silva J, Cerqueira F and Medeiros R. Chlamydia trachomatis infection: implications for HPV status and cervical cancer. Arch Gynecol Obstet. 2014; 289:715-723.

3. Farris CM and Morrison RP. Vaccination against Chlamydia genital infection utilizing the murine $\mathrm{C}$. muridarum model. Infect Immun. 2011; 79:986-996.

4. Swanson KA, Taylor LD, Frank SD, Sturdevant GL, Fischer ER, Carlson JH, Whitmire WM and Caldwell HD. Chlamydia trachomatis polymorphic membrane protein $\mathrm{D}$ is an oligomeric autotransporter with a higher-order structure. Infect Immun. 2009; 77:508-516.

5. Kubo A and Stephens RS. Characterization and functional analysis of PorB, a Chlamydia porin and neutralizing target. Mol Microbiol. 2000; 38:772-780.

6. Longbottom D. Chlamydial vaccine development. J Med Microbiol. 2003; 52:537-540.

7. Lu Y, Xiao Y, Ding J, Dierich $M$ and Chen YH. Immunogenicity of neutralizing epitopes on multipleepitope vaccines against HIV-1. Int Arch Allergy Immunol. 2000; 121:80-84.

8. Pumpens $\mathrm{P}$ and Grens E. HBV core particles as a carrier for B cell/T cell epitopes. Intervirology. 2001; 44:98-114.

9. Roose K, De Baets S, Schepens B and Saelens X. Hepatitis $\mathrm{B}$ core-based virus-like particles to present heterologous epitopes. Expert Rev Vaccines. 2013; 12:183-198.

10. Bax CJ, Quint KD, Peters RP, Ouburg S, Oostvogel PM, Mutsaers JA, Dorr PJ, Schmidt S, Jansen C, van Leeuwen AP, Quint WG, Trimbos JB, Meijer CJ et al. Analyses of multiple-site and concurrent Chlamydia trachomatis serovar infections, and serovar tissue tropism for urogenital versus rectal specimens in male and female patients. Sex Transm Infect. 2011; 87:503-507.

11. Petrovay F, Balla E, Nemeth I and Gonczol E. Genotyping of Chlamydia trachomatis from the endocervical specimens of high-risk women in Hungary. J Med Microbiol. 2009; 58:760-764.

12. Donati M, Di Francesco A, D'Antuono A, Pignanelli S, Shurdhi A, Moroni A, Baldelli R and Cevenini R. Chlamydia trachomatis serovar distribution and other concurrent sexually transmitted infections in heterosexual men with urethritis in Italy. Eur J Clin Microbiol Infect Dis.
2009; 28:523-526.

13. Zhu S, Chen J, Zheng M, Gong W, Xue X, Li W and Zhang L. Identification of immunodominant linear B-cell epitopes within the major outer membrane protein of Chlamydia trachomatis. Acta Biochim Biophys Sin (Shanghai). 2010; 42:771-778.

14. Eko FO, He Q, Brown T, McMillan L, Ifere GO, Ananaba GA, Lyn D, Lubitz W, Kellar KL, Black CM and Igietseme JU. A novel recombinant multisubunit vaccine against Chlamydia. J Immunol. 2004; 173:3375-3382.

15. Dong-Ji Z, Yang X, Shen C, Lu H, Murdin A and Brunham RC. Priming with Chlamydia trachomatis major outer membrane protein (MOMP) DNA followed by MOMP ISCOM boosting enhances protection and is associated with increased immunoglobulin A and Th1 cellular immune responses. Infect Immun. 2000; 68:3074-3078.

16. van Drunen Littel-van den Hurk S, Gerdts V, Loehr BI, Pontarollo R, Rankin R, Uwiera R and Babiuk LA. Recent advances in the use of DNA vaccines for the treatment of diseases of farmed animals. Adv Drug Deliv Rev. 2000; 43:13-28.

17. Stothard DR, Boguslawski G and Jones RB. Phylogenetic analysis of the Chlamydia trachomatis major outer membrane protein and examination of potential pathogenic determinants. Infect Immun. 1998; 66:3618-3625.

18. Sun G, Pal S, Weiland J, Peterson EM and de la Maza LM. Protection against an intranasal challenge by vaccines formulated with native and recombinant preparations of the Chlamydia trachomatis major outer membrane protein. Vaccine. 2009; 27:5020-5025.

19. Hafner LM and McNeilly C. Vaccines for Chlamydia infections of the female genital tract. Future Microbiol. 2008; 3:67-77.

20. de la Maza LM and Peterson EM. Vaccines for Chlamydia trachomatis infections. Curr Opin Investig Drugs. 2002; 3:980-986.

21. Zhu S, Feng Y, Rao P, Xue X, Chen S, Li W, Zhu G and Zhang L. Hepatitis B virus surface antigen as delivery vector can enhance Chlamydia trachomatis MOMP multi-epitope immune response in mice. Appl Microbiol Biotechnol. 2014; 98:4107-4117.

22. Xu W, Liu J, Gong W, Chen J, Zhu S and Zhang L. Protective immunity against Chlamydia trachomatis genital infection induced by a vaccine based on the major outer membrane multi-epitope human papillomavirus major capsid protein L1. Vaccine. 2011; 29:2672-2678.

23. Stevenson FK, Ottensmeier CH, Johnson P, Zhu D, Buchan SL, McCann KJ, Roddick JS, King AT, McNicholl F, Savelyeva N and Rice J. DNA vaccines to attack cancer. Proc Natl Acad Sci U S A. 2004; 101 Suppl 2:14646-14652.

24. Ercolini AM, Machiels JP, Chen YC, Slansky JE, Giedlen M, Reilly RT and Jaffee EM. Identification and characterization of the immunodominant rat HER-2/neu MHC class I epitope presented by spontaneous mammary 
tumors from HER-2/neu-transgenic mice. J Immunol. 2003; 170:4273-4280.

25. Eko FO, Talin BA and Lubitz W. Development of a Chlamydia trachomatis bacterial ghost vaccine to fight human blindness. Hum Vaccin. 2008; 4:176-183.

26. Berry LJ, Hickey DK, Skelding KA, Bao S, Rendina AM, Hansbro PM, Gockel CM and Beagley KW. Transcutaneous immunization with combined cholera toxin and $\mathrm{CpG}$ adjuvant protects against Chlamydia muridarum genital tract infection. Infect Immun. 2004; 72:1019-1028.

27. Lu H, Xing $Z$ and Brunham RC. GM-CSF transgenebased adjuvant allows the establishment of protective mucosal immunity following vaccination with inactivated Chlamydia trachomatis. J Immunol. 2002; 169:6324-6331.

28. Igietseme JU and Murdin A. Induction of protective immunity against Chlamydia trachomatis genital infection by a vaccine based on major outer membrane proteinlipophilic immune response-stimulating complexes. Infect Immun. 2000; 68:6798-6806.

29. Schneider-Ohrum K and Ross TM. Virus-like particles for antigen delivery at mucosal surfaces. Curr Top Microbiol Immunol. 2012; 354:53-73.

30. Roy P and Noad R. Virus-like particles as a vaccine delivery system: myths and facts. Hum Vaccin. 2008; 4:5-12.

31. Williams JA. Vector Design for Improved DNA Vaccine Efficacy, Safety and Production. Vaccines (Basel). 2013; 1:225-249.

32. Okuda K, Wada Y and Shimada M. Recent Developments in Preclinical DNA Vaccination. Vaccines (Basel). 2014; 2:89-106.

33. Wen L, Chen SJ, Zhang W, Ma HW, Zhang SQ and Chen L. hsBAFF regulates proliferation and response in cultured CD4(+) T lymphocytes by upregulation of intracellular free $\mathrm{Ca}(2+)$ homeostasis. Cytokine. 2011; 53:215-222.

34. Howe RC, Wondimu A, Demissee A and Frommel D. Functional heterogeneity among CD4+ T-cell clones from blood and skin lesions of leprosy patients. Identification of T-cell clones distinct from Th0, Th1 and Th2. Immunology. 1995; 84:585-594.

35. Schodel F, Moriarty AM, Peterson DL, Zheng JA, Hughes JL, Will H, Leturcq DJ, McGee JS and Milich DR. The position of heterologous epitopes inserted in hepatitis B virus core particles determines their immunogenicity. J Virol. 1992; 66:106-114.

36. Greene W, Xiao Y, Huang Y, McClarty G and Zhong G. Chlamydia-infected cells continue to undergo mitosis and resist induction of apoptosis. Infect Immun. 2004; 72:451460.

37. Alexander J, Sidney J, Southwood S, Ruppert J, Oseroff C, Maewal A, Snoke K, Serra HM, Kubo RT, Sette A and et al. Development of high potency universal DR-restricted helper epitopes by modification of high affinity DRblocking peptides. Immunity. 1994; 1:751-761.

38. Alexander J, Fikes J, Hoffman S, Franke E, Sacci J, Appella
E, Chisari FV, Guidotti LG, Chesnut RW, Livingston B and Sette A. The optimization of helper T lymphocyte (HTL) function in vaccine development. Immunol Res. 1998; 18:79-92.

39. Kashi VP, Jacob RA, Shamanna RA, Menon M, Balasiddaiah A, Varghese RK, Bachu M and Ranga U. The grafting of universal T-helper epitopes enhances immunogenicity of HIV-1 Tat concurrently improving its safety profile. PLoS One. 2014; 9:e114155.

40. Wizemann $\mathrm{H}$ and von Brunn A. Purification of E. coliexpressed HIS-tagged hepatitis B core antigen by Ni2+ -chelate affinity chromatography. J Virol Methods. 1999; 77:189-197.

41. Vogel M, Diez M, Eisfeld J and Nassal M. In vitro assembly of mosaic hepatitis B virus capsid-like particles (CLPs): rescue into CLPs of assembly-deficient core protein fusions and FRET-suited CLPs. FEBS Lett. 2005; 579:5211-5216.

42. Holland MJ, Conway DJ, Blanchard TJ, Mahdi OM, Bailey RL, Whittle HC and Mabey DC. Synthetic peptides based on Chlamydia trachomatis antigens identify cytotoxic $\mathrm{T}$ lymphocyte responses in subjects from a trachoma-endemic population. Clin Exp Immunol. 1997; 107:44-49.

43. Starnbach MN, Bevan MJ and Lampe MF. Murine cytotoxic $\mathrm{T}$ lymphocytes induced following Chlamydia trachomatis intraperitoneal or genital tract infection respond to cells infected with multiple serovars. Infect Immun. 1995; 63:3527-3530. 